\title{
O MERCADO FINANCEIRO CHEGA À SALA DE AULA: EDUCAÇÃO FINANCEIRA COMO POLÍTICA PÚBLICA NO BRASIL
}

\author{
Márcia Pereira Cunha ${ }^{1,2}$ (D
}

\begin{abstract}
RESUMO: O objetivo do artigo é descrever e analisar a implementação da Estratégia Nacional de Educação Financeira no Brasil, destacando dois aspectos de seu desenho institucional: a simbiose entre instituições públicas e do mercado financeiro e sua localização no interior de uma rede transnacional promotora da Educação Financeira em diversos países. Defende-se que essas características beneficiam a introdução, no ambiente escolar, de conteúdos e valores cujos objetivos pedagógicos associam-se a um projeto de sociedade pouco nítido e não discutido pelos atores sociais interessados. Recorre-se a documentos, legislação e publicações produzidas pelos órgãos promotores desta experiência, de forma a reconstituir suas bases e caracterizar uma forma nova e recente de incidência sobre a educação no Brasil.
\end{abstract}

Palavras-chave: Educação Financeira. OCDE. ENEF. Inclusão Financeira.

\section{THE FINANCIAL MARKET REACHES THE CLASSROOM: FINANCIAL EDUCATION AS A PUBLIC POLICY IN BRAZIL}

\begin{abstract}
This article aims to describe and analyze the implementation of the National Financial Education Strategy in Brazil, highlighting two aspects of its institutional design: the symbiosis between public institutions and financial market entities and its location within a transnational network of organizations promoting Financial Education in several countries. It is argued that these characteristics benefit the introduction, in the school environment, of contents and values whose pedagogical objectives are associated to a project of society that is not clear and was not discussed by the social actors involved. Based on documents, legislation and publications produced by the bodies that promote this experience, the article reconstitutes it and characterize it as a new and recent form of incidence on education in Brazil.
\end{abstract}

Keywords: Financial Education. OECD. ENEF. Financial Inclusion.

1.Universidade de São Paulo - Laboratório Misto Internacional - São Paulo (SP), Brasil. E-mail: marcia.cunha@gmail.com 2.Université Paris Nanterre - Laboratório Sophiapol - Paris, França. E-mail: marcia.cunha@gmail.com

Este artigo resulta de pesquisa financiada pelo Programa Nacional de Pós-doutorado da Capes (PNPD-Capes), realizada no departamento de Sociologia da Unicamp. 


\title{
EL MERCADO FINANCIERO LLEGA AL AULA: LA EDUCACIÓN FINANCIERA COMO POLÍTICA PÚBLICA EN BRASIL
}

\begin{abstract}
RESUMEN: El objetivo del artículo es describir y analizar la implementación de la Estrategia Nacional para la Educación Financiera en Brasil, destacando dos aspectos de su diseño institucional: la simbiosis entre instituciones públicas y financieras y su ubicación dentro de una red transnacional que promueve la Educación Financiera en varios países. Se argumenta que estas características benefician la introducción en el ambiente escolar de contenidos y valores cuyos objetivos pedagógicos están asociados con un proyecto de sociedad poco claro y no discutido por los actores sociales involucrados. Utilizamos documentos, legislación y publicaciones producidas por las agencias que promueven esta experiencia, con el fin de reconstruir sus bases y caracterizar una nueva y reciente forma de incidencia en la educación en Brasil.
\end{abstract}

Palabras-clave: Educación Financiera. OCDE. ENEF. Inclusión Financiera.

\section{Introdução}

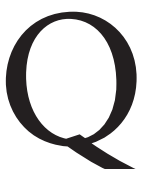

uando Reinhard Bendix (1996) analisa a consolidação da educação como um direito social específico - no processo mais amplo de construção de Estados Nacionais e dos componentes de cidadania - afirma, olhando para a história, que esta área sempre foi alvo de disputa entre grupos sociais portadores de visões de mundo e interesses diversos. Se o lugar e o papel dos Estados-Nação se transformaram muito de lá para cá, fazendo-se objeto de investigação e debate tanto quanto os conteúdos que diferentes grupos tentam introduzir na formação de crianças e jovens, o fato mesmo da disputa parece ter se mantido uma constante. Dessa perspectiva, propomos abordar uma investida recente sobre o ambiente escolar que articula conteúdo e forma de extrema atualidade: as iniciativas de Educação Financeira.

No que se refere ao conteúdo, Educação Financeira é, segundo seus promotores,

\footnotetext{
o processo mediante o qual os indivíduos e as sociedades melhoram a sua compreensão em relação aos conceitos e produtos financeiros, de maneira que, com informação, formação e orientação, possam desenvolver os valores e as competências necessários para se tornarem mais conscientes das oportunidades e riscos neles envolvidos e, então, poderem fazer escolhas bem informadas, saber onde procurar ajuda e adotar outras ações que melhorem o seu bem-estar. Assim, podem contribuir de modo mais consistente para a formação de indivíduos e sociedades responsáveis, comprometidos com o futuro ${ }^{1}$.
}

Embora a expressão seja passível de aplicação a amplo leque de atividades formativas, a que tomamos como objeto está associada a um corpo específico de iniciativas (designado como Inclusão Financeira), desenvolvido, nos anos 2000, por um conjunto diverso e numeroso de organizações privadas e públicas, nacionais e internacionais. Daí o que destacamos no que se refere à forma: sua natureza transnacional.

Com base em análise de documentos produzidos pelas principais entidades e órgãos promotores da Educação Financeira, examinamos o desenho de sua organização e implementação e discutimos as dificuldades que a estrutura criada gera para a compreensão e participação da comunidade escolar na definição dos meios de trabalho e justificativas sobre a pertinência do tema como conteúdo pedagógico. Em 
diálogo com a reflexão proposta por Nancy Fraser (2009) acerca das questões que o transbordamento das fronteiras dos Estados nacionais, por processos políticos e econômicos, coloca para o problema da justiça, propomos tomar a Educação Financeira como uma experiência concreta que abarca, de uma só vez, ações que conectam o plano internacional aos âmbitos locais de diversos países do globo e que disseminam uma visão de mundo ancorada na centralidade de noções, dinâmicas e percepções referidas ao universo financeiro. A este respeito, a prioridade dada à educação e, em especial, à educação escolar, pelos artífices da Educação Financeira, parece refletir, como assinalou Bendix, um projeto de sociedade; neste, vê-se a concepção de mundo que vislumbram e que pretendem controlar.

$\mathrm{O}$ artigo está organizado em três seções, além desta introdução e das considerações finais. Na primeira, apresentamos as origens institucionais da Educação Financeira no plano internacional. Sendo a Organização para Cooperação e Desenvolvimento Econômico (OCDE) reconhecidamente ativa no campo de políticas de educação, buscamos localizar esse braço específico de sua atuação no contexto mais amplo pós-crise financeira de 2008. Na segunda seção, apresentamos o espelhamento organizacional no contexto brasileiro: os atores envolvidos, os campos de atuação, o modus operandi. Na terceira, propomos discutir algumas questões que este caso oferece quanto às condições de autonomia e autodeterminação da educação frente aos interesses e influências advindas das confluências entre público e privado, global e local. A escolha de enfatizar a armação institucional e seus consequentes efeitos de ofuscamento de espaços de participação e tomada de decisão em detrimento de análise exaustiva de conteúdo se justifica, acreditamos, pela possibilidade de que futuros trabalhos nessa linha possam se beneficiar do registro e problematização do contexto em que esses conteúdos se originaram, de forma a desnaturalizar sua adoção.

\section{Educação Financeira como plano global}

Falar em educação financeira ${ }^{2}$ não necessariamente remete a ensino formal, nem a um conjunto bem-delimitado de temas a tratar. No Brasil, uma tentativa de mapear trabalhos nesta área identificou instituições, ações e conteúdos dirigidos a, no geral, adultos consumidores ou interessados em produtos comercializados pelo sistema financeiro (Savoia et al., 2007). Nesses casos, eram as próprias instituições que forneciam materiais informativos e desenvolviam atividades de cunho educativo. Configuração semelhante deve estar na origem de uma diferenciação feita pela OCDE entre educação financeira e proteção ao consumidor, quando esta organização realizou levantamento de iniciativas em diferentes países. Grosso modo, proteção ao consumidor trata de oferta de informação no plano da legislação e regulação que garante padrões de atendimento e salvaguarda aos clientes dos serviços. Educação Financeira ${ }^{3}$, por sua vez, "complementa esta informação com a provisão de instrução e aconselhamento” (OCDE, 2005a, p. 14). Esta delimitação muito inicial ganhou mais elementos com o passar do tempo, mas manteve inalterado seu foco sobre o comportamento, sobre a atitude individual.

No plano internacional, a OCDE é a principal referência no tocante à produção de conteúdos e validação de experiências de Educação Financeira. Sua primeira incursão sistemática neste campo se deu no início dos anos 2000, com a criação do Financial Education Project, em 2003. A iniciativa se justificava pela preocupação, demostrada por países membros, com três processos em curso: o aumento de trabalhadores a se aposentar em cenário de diminuição da cobertura previdenciária promovida por Estados e empregadores; o aumento do endividamento em condições de acesso facilitado a crédito e a mercados financeiros desregulados e o aumento de transações financeiras eletrônicas, em contexto onde há grupos sociais fora do sistema bancário (OCDE, 2005a, p. 11). É neste âmbito que a organização realiza o inventário e a análise das ações ao 
redor do mundo que mencionamos há pouco. Ao lado dos resultados do mapeamento, além de diferenciar educação financeira de proteção ao consumidor, o relatório adianta a relevância de desdobrá-la com especificidade para instituições escolares, dada a importância percebida de "educar indivíduos tão cedo quanto possível sobre questões financeiras" (idem).

Em 2008, as ações ganham novo impulso com a criação da International Network on Financial Education (INFE), rede que reúne experts e representantes de instituições públicas de diversos países (membros ou não $)^{4}$. A rede se apresenta como uma plataforma que reúne dados coletados nos países para identificar boas práticas e produzir recomendações e instrumentos de gestão de políticas nacionais. Esse robustecimento institucional se dá no mesmo cenário em que, depois da crise financeira de 2008, os países do G20, no encontro de 2009, decidem formalizar a criação de uma rede dedicada à promoção do que nomeiam como Inclusão Financeira, a Global Partnership for Financial Inclusion (GPFI). A variedade de atores (públicos e privados, nacionais e internacionais) e campos de atuação (microsseguros, microcrédito e bancarização abrindo-se a outros complementares) dá origem a um edifício institucional bastante complexo e tentacular (Cunha, 2018, p. 588-9). Seu objetivo de criação e oferta de serviços e produtos financeiros para grupos de baixa renda, por sua vez, estabelece ligação com o tema da Educação Financeira, de forma que a OCDE seja uma das organizações parceiras da GPFI e suas diretrizes sejam sempre citadas.

Neste ponto vale uma pequena nota sobre a diversidade de experiências de Educação Financeira no plano internacional. Esta estreita relação entre Educação e Inclusão Financeira é fundante em alguns países, entre eles o Brasil. Lazzarus (2013) assinala o fato de que precursores como Reino Unido, Estados Unidos e Nova Zelândia dirijam suas ações privilegiadamente às classes médias, enquanto na retardatária França a tônica seja a abordagem dos mais pobres. No caso brasileiro, a Educação Financeira surgiu fortemente como uma ação subsidiária da Inclusão Financeira num contexto de políticas de estímulo ao consumo; fazendo referência, portanto, a classes sociais mais vulneráveis. Como apoiadora da pretendida expansão do mercado de produtos e serviços financeiros, é ela quem vai formar os indivíduos que vão adquiri-los. Nesse sentido, a preocupação com a diminuição dos sistemas de proteção social públicos, com o endividamento e a bancarização adquire mais nuances no que contém de preparação de famílias e indivíduos para entrada em um novo mercado, também em vias de consolidação.

Invariável, por outro lado, é a colaboração entre INFE e GPFI: orienta programas de proteção de consumidores, oferece instrumentos para avaliação de programas de Educação Financeira e para medição de nível de letramento financeiro e, finalmente, produz e dissemina diretrizes e instrumentos para o desenvolvimento de estratégias nacionais de Educação Financeira em escolas e para outros grupos, como mulheres, imigrantes, idosos. No final de 2009, o Rio de Janeiro recebeu a OECD-Brazilian International Conference on Financial Education, ocasião em que se reafirmou que o "objetivo de aumentar o conhecimento e as competências financeiras de estudantes e crianças na escola se tornou alta prioridade, assim como importante desafio para formuladores de políticas ao redor do mundo" (OCDE, 2010, p. 6). Reafirmaram-se, ainda, os parâmetros que deveriam orientar as ações de Educação Financeira nas escolas:

ela deveria preferencialmente ser desenvolvida por meio de um programa planejado e coerente, receber recursos adequados, envolver avaliação rigorosa, ser oferecida tão cedo quanto possível, ser incluída no currículo escolar como elemento obrigatório (como tema em si ou incorporado a outros temas) e focar no desenvolvimento de atitudes, habilidades, conhecimento financeiros, bem como comportamentos financeiros responsáveis (idem).

A cooperação entre Brasil e OCDE para disseminação da Educação Financeira no país e na América Latina foi anunciada na mesma ocasião, bem como a inclusão do tema na avaliação internacional 
de nível educacional realizada pela organização, o PISA (Programme for International Student Assessment), o que foi feito em 2012. A segunda década do século XXI se inicia, portanto, com uma estrutura institucional no Brasil que replica as instituições criadas no âmbito internacional: o Banco Central do Brasil liderou a criação, em 2011, da Parceria Nacional para Inclusão Financeira, espelhando a GPFI. A recomendação pela OCDE de criação de estratégias nacionais de Educação Financeira pelos países ganhou corpo no Brasil por meio de Decreto Federal 7.397, de 22 de dezembro de 2010, que criou a Estratégia Nacional para Educação Financeira.

\section{Estratégia Nacional para Educação Financeira}

Desde 2007, entretanto, já se organizavam ações para implementar a Educação Financeira no Brasil, com anunciado status de política de Estado. O Comitê de Regulação e Fiscalização dos Mercados Financeiro, de Capitais, de Seguros, de Previdência e Capitalização $\left(\right.$ Coremec $\left.^{5}\right)$, do Ministério da Fazenda, instituiu grupo de trabalho, coordenado pela Comissão de Valores Mobiliários, para elaboração de uma proposta de Estratégia Nacional de Educação Financeira, tarefa finalizada em 2009. Neste documento, é apresentado como objetivo da ENEF:

promover e fomentar a cultura de educação financeira no país, ampliar a compreensão do cidadão, para que seja capaz de fazer escolhas conscientes quanto à administração de seus recursos, e contribuir para eficiência e solidez dos mercados financeiro, de capitais, de seguros, de previdência e de capitalização (CVM, s/d.a, p. 2).

A Tabela 1 apresenta a atual estrutura organizacional (ou de governança, segundo seus próprios termos) da ENEF.

A ENEF tem suas ações organizadas em dois tipos: setoriais e transversais. As chamadas setoriais designam projetos desenvolvidos autonomamente pelas entidades ou órgãos que compõem a Estratégia. As chamadas transversais são as que ganharam vida especificamente no âmbito da Estratégia Nacional e são desenvolvidas sob coordenação da Associação para Educação Financeira (AEF), organização da sociedade civil de interesse público (OSCIP) criada em $2011^{6}$ pelas quatro instituições citadas na Tabela 1. (ANBIMA, B3, CNSeg e FEBRABAN) exclusivamente para este fim. Essas ações organizam-se, por sua vez, em três frentes: Mapeamento Nacional das Iniciativas de Educação Financeira, Educação Financeira de Adultos e Educação Financeira nas Escolas, a que privilegiamos aqui.

As primeiras ações nas escolas se deram entre 2010 e 2011, envolvendo alunos do ensino médio. O conteúdo de três livros produzidos conjuntamente pelo CONEF/GAP (de temas "Vida Familiar Cotidiana", "Empreendedorismo" e "Bens Públicos") orientaram atividades desenvolvidas por 1.200 professores de matemática, português, ciências, geografia e história (devidamente formados nos conteúdos tratados), junto a 26.981 alunos de Ensino Médio de 891 escolas de $\operatorname{cinco~estados~}^{7}$ (SP, RJ, MG, TO, CE) e DF (AEF, 2012, p. 14). Essas atividades foram realizadas dentro de um desenho que se definia como experimental, com vistas a avaliação: escolha randômica das escolas, estabelecimento de "grupos de tratamento" e "grupos de controle" e aplicação de instrumentos de avaliação em três momentos (inicial, intermediário e final). Familiares dos alunos também foram envolvidos e avaliados. Os relatórios e documentos destacam os resultados positivos: “o programa levou a maior proficiência financeira, autonomia financeira e intenção de poupar; levou a poupança e comportamento de gastos aprimorados, assim como a maior participação dos alunos nas finanças domiciliares" (BMF\&Bovespa, 2012, p. 3). 
Tabela 1. Estrutura Organizacional para a Estratégia Nacional de Educação Financeira ${ }^{1}$

\begin{tabular}{|c|c|c|c|}
\hline \multirow{2}{*}{ Esfera } & \multirow{2}{*}{ Instituição } & \multicolumn{2}{|c|}{ Participantes } \\
\hline & & Órgãos do governo & Sociedade civil \\
\hline Estratégica & $\begin{array}{l}\text { Comitê Nacional } \\
\text { de Educação } \\
\text { Financeira } \\
\text { (CONEF) }\end{array}$ & $\begin{array}{l}\text { - Banco Central do Brasil } \\
\text { - Comissão de Valores Mobiliários } \\
\text { - Superintendência Nacional de } \\
\text { Previdência Complementar } \\
\text { - Superintendência de Seguros } \\
\text { Privados } \\
\text { - Ministério da Justiça e Cidadania } \\
\text { - Ministério da Previdência Social } \\
\text { - Ministério da Educação } \\
\text { - Ministério da Fazenda }\end{array}$ & $\begin{array}{l}\text { - Associação Brasileira das } \\
\text { Entidades dos Mercados } \\
\text { Financeiros e de Capitais } \\
\text { (ANBIMA) } \\
\text { - } \text { B3 }^{3} \\
\text { - Conferederação Nacional } \\
\text { das Empresas de Seguros } \\
\text { Gerais, Previdência Privada } \\
\text { e Vida, Saúde Suplementar e } \\
\text { Capitalização (CNSeg) } \\
\text { - Federação Brasileira de Bancos } \\
\text { (FEBRABAN) }\end{array}$ \\
\hline Consultiva & $\begin{array}{l}\text { Grupo de Apoio } \\
\text { Pedagógico } \\
(\text { GAP })^{2}\end{array}$ & $\begin{array}{l}\text { - Banco Central do Brasil } \\
\text { - Comissão de Valores Mobiliários } \\
\text { - Superintendência Nacional de } \\
\text { Previdência Complementar } \\
\text { - Superintendência de Seguros } \\
\text { Privados } \\
\text { - Ministério da Educação } \\
\text { - Ministério da Fazenda } \\
\text { - Ministério da Previdência Social }{ }^{4} \\
\text { - Ministério da Justiça e Cidadania } \\
\text { - } 5 \text { Instituições Federais de Ensino, } \\
\text { sendo uma por região brasileira } \\
\text { - Conselho Nacional de Educação } \\
\text { - Conselho dos Secretários de } \\
\text { Educação } \\
\text { - União dos Dirigentes Municipais } \\
\text { de Educação }\end{array}$ & \\
\hline Coordenação & $\begin{array}{c}\text { Associação } \\
\text { de Educação } \\
\text { Financeira do } \\
\text { Brasil (AEF) }\end{array}$ & & $\begin{array}{l}\text { - ANBIMA } \\
\text { - } \mathrm{B} 3 \\
\text { - CNseg } \\
\text { - FEBRABAN }\end{array}$ \\
\hline
\end{tabular}

${ }^{1}$ Segundo portal da ENEF (http://www.vidaedinheiro.gov.br/), consulta em 06/12/2017. Em consulta em 31/12/2018, o Sebrae e o Conselho Nacional de Secretários de Educação (estados e DF) apareciam acrescentados aos representantes da sociedade civil no CONEF. ${ }^{2}$ Agrega, ainda, a Secretaria Executiva, exercida pelo Banco Central e uma comissão de suporte técnico, com a mesma composição do CONEF. ${ }^{3}$ Empresa resultante da fusão da Bolsa de Valores, Mercadorias e Futuros com empresa CETIP, para oferta de serviços de consultoria financeira. ${ }^{4}$ Algumas das fontes consultadas não mencionam esse ministério.

Em 2013, a AEF formalizou parceria com o MEC para disseminação da Educação Financeira para o ensino médio (AEF, 2013), sendo escolhidas escolas que já participavam de outros programas do governo federal ${ }^{8}$. Foi definida como meta para o biênio 2014-15 a extensão do programa para 3 mil escolas em todo o país e o aumento do número de secretarias estaduais a "aderir" à ENEF (idem, p. 21). Neste processo de expansão, os profissionais das secretarias recebem formação e atuam como "multiplicadores”, isto é, transmitem o conteúdo aprendido aos profissionais das escolas (que contam, também com ferramentas de educação à distância fornecidas diretamente pelos executores da ENEF). Neste período também se desenhou o alcance dos alunos de ensino fundamental, contando com o mesmo processo: desenvolvimento 
de material didático (um livro para cada ano, totalizando nove livros), formação de gestores e professores e piloto controlado, com fins avaliativos, no ano de 2015. Foram envolvidas 201 escolas em dois municípios (Manaus e Joiville) e aplicados questionários e testes a alunos, familiares e professores. Além de questões para definir os perfis socioeconômicos, havia perguntas dirigidas especificamente a cada segmento. Junto aos alunos, buscou-se avaliar a apreensão de conteúdos e a mudança de atitudes e comportamentos; aos pais, foram feitas perguntas sobre atitudes e comportamentos; aos professores, perguntou-se sobre a aplicação dos materiais pedagógicos desenvolvidos para a Educação Financeira. A apresentação dos resultados pontua variações mais positivas ou menos entre competências ou atitudes, leitura acompanhada, por vezes, de tentativas de interpretações à luz dos perfis socioeconômicos. O que nos interessa colocar para discussão é menos o teor da avaliação (que não é nosso foco) e mais o tipo de consequência que se produz a partir dela. A análise da utilização dos materiais didáticos é significativa a esse respeito: segundo narra o relatório, a coleta de dados no meio do ano revelou que o emprego de recursos e livros do projeto, pelos professores, havia sido menor que o previsto por seus proponentes, ocasionando intervenção (não descrita) para correção do problema. Coleta de dados no final do ano atestou, então, melhora deste aspecto, com "mais da metade" dos docentes tendo cumprido "mais de 60\% do conteúdo programado" (AEF, 2016b, p. 8). O relatório conclui, assim, que "a implementação ainda apresenta desafios” (AEF, 2016b, p. 9), sendo necessário repensar formatos e estratégias para produzir “intensidade” o que, subentende-se, depende do trabalho com todo o conteúdo tal como idealizado. Essa afirmação dá a dimensão tanto da disposição pelos implementadores da AEF para interferência, quanto da convicção acerca do domínio dos meios para realizá-la, atingindo o cerne do processo educativo, que é a atuação das professoras e professores em sala de aula.

Essa disposição, entretanto, não se limita a induzir a realização de determinadas atividades, de determinadas formas e com determinados objetivos. De maneira similar, a tarefa de multiplicar conteúdos, atribuída a gestores e professores que recebem cursos de capacitação no tema, não esgota a justificativa para a necessidade de "sensibilização" destes dois grupos (CVM, s/d.b: 30). A atenção dada ao problema da adesão ganha clareza na perspectiva mesmo das diretrizes da OCDE. No caso dos gestores, a primeira refere-se à orientação de que a implementação de estratégias nacionais de Educação Financeira deveria privilegiar a criação de uma instituição específica “inserida no interior das agências existentes" (OCDE, 2005b: s/p). O acoplamento das instituições reunidas na ENEF à estrutura pública de formulação e gestão da política educacional no Brasil (do nível mais centralizado aos mais descentralizados) responde a essa orientação. A segunda diretriz diz respeito à concepção da Educação Financeira como "um processo para a vida, constante e contínuo" (idem). Na apreensão brasileira dessa coordenada, trata-se de assumir que as almejadas mudanças de atitude e comportamento serão obtidas apenas no longo prazo, o que reforça a adequação do desenho institucional.

Como a perseverança é crucial para o processo da introdução da Educação Financeira nas escolas, é muito importante que os gestores escolares tenham suporte suficiente para poderem liderar com segurança as necessárias mudanças que deverão empreender nas suas escolas (CVM, s/d.b: 30).

A ênfase sobre o professor compartilha desse tipo de justificativa, mas acrescenta elementos que iluminam perspectivas especificamente atribuíveis a este profissional. Em documento de 2017, fala-se de "nova fase do Programa de Educação Financeira nas Escolas [que] reuniu uma série de ações para tornar o educador o protagonista no processo" (AEF, 2017, p. 8). Se, no caso do gestor, trata-se de instrumentalizar a 
estrutura institucional existente para suporte das ações, no caso do professor o foco está em seu "engajamento" para "motivar" alunos e familiares na assimilação dos conteúdos e mudanças de comportamento. Idealmente conhecedor da realidade em que, por ofício, está inserido, faz sentido que seja tomado como o "principal agente" (AEF, 2016a, p. 6) por estar na ponta de uma cadeia sustentada pela ideia de que é preciso estar "tão perto da população quanto possível” (OCDE, 2005b: s/p.). Por isso, para que os professores possam "transmitir adequadamente esses conceitos, é essencial que entendam a importância em controlar as finanças e que prevejam os resultados benéficos que essa atitude poderá trazer em curto, médio e longo prazo tanto para o indivíduo como para a sociedade" (CVM, s/d.a, p. 99).

O entendimento da "importância" do tema passa pelo convencimento genuíno do educador, tendo pouco ou nada a ver com a proposição de um exercício intelectual de elaboração e construção das justificativas pedagógicas para a iniciativa. Isso não deve ser entendido, entretanto, como objetivo de controle inflexível da prática do professor. Ao contrário, a afirmação da garantia de sua liberdade e uso de sua criatividade para adaptar conteúdos à realidade local é recorrente. O comprometimento é central por isso: pode garantir a apreensão daquele repertório a despeito de variações internas ou colorações locais - pluralidade controlada que concorre para a replicação coesa e coerente do vocabulário, dos recursos e dos valores implicados neste universo.

\section{Disputar a educação através das fronteiras}

A presença da iniciativa privada e as interferências de organizações internacionais na educação vêm sendo analisadas há muito tempo pelos especialistas da área. Discutindo as mudanças sofridas pela instituição escolar no contexto francês, Laval et al. (2011) dão centralidade ao problema da perda de autonomia para a definição do que chamam de "nova escola capitalista". Os autores lembram a sociologia crítica dos anos de 1960/70 que desvelou, no funcionamento da escola, processos que se combinavam à reprodução da estrutura social desigual, discussão que tem em Pierre Bourdieu sua principal referência (1992). No entanto, prosseguem, o desvelamento dessa afinidade implicava captar uma contradição com relação aos objetivos emancipadores da educação escolar, contradição que afirma, em contrapartida, a existência de autonomia da instituição. Que os conteúdos ensinados atendessem às necessidades de reprodução da sociedade capitalista não era o mesmo que os reduzir a sua utilidade econômica. A "nova escola capitalista", diferentemente, caracteriza-se por sua crescente sujeição às necessidades econômicas - sujeição em termos de funcionamento e de conteúdos ensinados. Trata-se de produzir sujeitos que atendam às demandas do mercado de trabalho, mas, na mesma medida - e isso fica evidenciado no caso da educação financeira que os autores também mencionam - aos mercados de novos produtos e serviços. Em suas palavras, "formar indivíduos adaptáveis e personalidades fluidas" (Laval et al., 2011, p. 11). Consequentemente, esses passam a ser os parâmetros pelos quais são julgados os estabelecimentos, seus méritos e seu papel social. A utilidade econômica tende a sobrepor-se, como valor, ao conhecimento que vale por si só. Assim, se a "nova escola capitalista" não é, como afirmam Laval et al., o nome de uma sentença ao final de um processo terminado e/ou irreversível, o acolhimento da natureza absolutamente utilitária da proposta de Educação Financeira indica a validade da imagem para pensar este momento da educação no Brasil.

Nesta linha, a Educação Financeira poderia ser tomada apenas como uma manifestação explícita e caricatural diante de outras formas mais sutis dessa influência. No entanto, a maneira como ela se dá não é nada trivial. Ainda segundo os autores, não é o caso de tomar as escolas como vítimas de intervenções puramente exteriores. Como instituições sociais que são, estão expostas às tendências de transformação 
que atingem o conjunto da sociedade, de modo que envolvem sempre agentes internos e externos com posições distintas a respeito das proposições e atuações que abrigam. Daí a importância de contextualizar essas iniciativas e interrogar a obviedade atribuída a sua afirmação. Em cenário em que o processo de financeirização em si é objeto de espinhoso debate, é razoável que as escolas sejam colocadas de um dos lados da contenda? A iniciativa deve ser tomada como preparação para este mundo financeirizado que os promotores da Educação Financeira afirmam existir ou como parte do processo de sua produção mesma, ao formar indivíduos em sua gramática específica?

Essas perguntas colocam em evidência outra ordem de problemas: a reorganização institucional dos espaços relevantes na definição do que se refere à educação. Partindo do mesmo cenário de transformações, Afonso (2001) discute a autonomia nesta segunda chave, considerando o contexto de intensificação dos processos de globalização. Tratando das divergências e enfrentamentos em torno de proposições acerca do problema da reforma do Estado, o autor alerta contra leituras que descartam a relevância dos Estados nacionais reconhecendo, entretanto, mudanças de função. Trata-se, segundo ele, de questão central para pensar políticas educacionais, pois neste cenário "novas instâncias de regulação supranacional” juntam-se a organizações mais antigas, como Banco Mundial e OCDE, na indução dos Estados a assumirem novas funções, de "mediação, de adequação às prioridades externamente definidas ou, mesmo, promoção de agendas que se circunscrevem a ditames mais ou menos ortodoxos da fase atual de transnacionalização do capitalismo e de globalização hegemônica" (Afonso, 2001, p. 24). A experiência da Educação Financeira corresponde em grande medida a essa descrição.

Ao entrar nas escolas por meio dos diferentes níveis da estrutura de gestão da execução da política, a ENEF aloja-se também nas estruturas que implicam em diferenças hierárquicas de poder e tomada de decisão, tornando chave a questão da delimitação dos espaços de disputa. Ou seja, aquela afirmação da necessidade de todo o conteúdo ser aplicado pelo professor, de forma a propiciar a obtenção dos resultados esperados, no exemplo há pouco citado, se assenta sobre um encadeamento de escolhas e concepções construídas em âmbitos aos quais esses atores não têm acesso. E a falta de acesso não decorre, usando as palavras de Nancy Fraser (2009), de um problema de falha nos mecanismos institucionais de representatividade ${ }^{10}$. A falta de acesso decorre dessa transformação na delimitação dos espaços de disputa que, por isso, é preciso compreender para redefinir ou reinventar estratégias de participação.

Para melhor apreender a contribuição da discussão da autora, vale breve menção a sua proposta, desenvolvida em meados dos 1990, de pensar os caminhos para alcance de justiça social articulando as dimensões material de distribuição e sociocultural de reconhecimento (Fraser, 1995). Nos anos 2000, a autora recupera sua própria produção afirmando que ela tomava como dada a referência estabelecida dos Estados nacionais. Referindo-se a este modelo como modelo keynesiano-westfaliano (Fraser, 2009), questiona sua evidência ao indicar uma diversidade de problemas enfrentados pela sociedade contemporânea cujas causas se enraízam em espaços não coincidentes com as unidades territoriais delimitadas por ele. Assim, apreender corretamente as injustiças, bem como as formas de enfrentá-las, exigiria acrescentar uma nova dimensão ao plano analítico: além das dimensões econômica e cultural, a dimensão política. Isso porque neste âmbito é possível abarcar questões relacionadas não só ao conteúdo da justiça, mas também aos critérios de definição de seus sujeitos, antes tomados como dados pelas fronteiras dos Estados nacionais.

Fraser busca, assim como Afonso, desenvolver uma formulação que se adeque a esse contexto em que às hierarquias espaciais e institucionais consolidadas e conhecidas somam-se novos desenhos e, com eles, novos dilemas. A problematização a respeito da definição de quem são os sujeitos contribui para o entendimento dos efeitos discretos da interação entre o nacional e o supranacional, na medida em que coloca em debate a possibilidade de nomear e implicar os reais interlocutores, de identificar claramente seus 
recursos de poder, de modo que todos os interessados possam se situar de maneira corretamente informada e em pé de igualdade no mesmo terreno. A Educação Financeira, atravessando e estabelecendo continuidade entre os planos internacional, nacional e local, suscita questão similar. O isolamento entre, de um lado, seus formuladores e, de outro, os atores cujo envolvimento está previsto e planejado, se dá por esta zona cinzenta em que estão abrigados os primeiros. A despeito disso, a divisão de tarefas está consolidada: objetivos, conteúdos e métodos definidos no plano internacional, e o poder público abrindo passagem para que as instituições de mercado os introduzam, tendo já operado uma primeira tradução que os adeque ao contexto nacional. Para isso, além do uso da estrutura pública, contam também com consultores e educadores, o que lhes garante qualidade e legitimidade. Não é à toa que gestores e profissionais sejam também públicos a educar, prospectando-se seus papéis de "multiplicadores". O conhecimento que cada professor detém sobre o nível local, por fim, cria os laços e sentidos necessários para a incorporação dos conteúdos.

Assim sendo, por seu conteúdo e por sua forma, a Educação Financeira abre perspectivas privilegiadas para apreensão dos sentidos e direções em que elites políticas e econômicas vêm se movimentando. No tocante ao conteúdo, a formação de um sujeito que delineia a ideia de sociedade a que ele deve se adequar. Na forma, o amálgama de instituições diversas, coordenadas por objetivos e visões de mundo definidos, porém pouco nítidos. É certo que ainda há muito que se discutir a respeito dos efeitos da inserção de tais conteúdos na educação escolar, e esse trabalho será tanto mais rico quanto mais informado sobre as condições que se impõem à efetividade de suas conclusões. A estrutura e o funcionamento que constituem a empreitada da Educação Financeira nas escolas traduzem uma ação que se hospeda na estrutura de gestão da política, que se pretende e se apresenta como perene, com objetivos de longo prazo, em nome do cumprimento de uma agenda internacional que se estende não só a uma concepção internacional de educação (a financeira, desenvolvida pela OCDE) mas, principalmente, a um ideário enraizado em âmbito alheio ao da educação, que é o da Inclusão Financeira, e de todo o contexto que a acompanha. Dito de outra maneira, enraizado menos em problematizações acerca de abordagens educacionais de questões atuais e mais em receituário que legitima uma resposta particular a tais questões. A Educação Financeira pressupõe e carrega consigo um diagnóstico da realidade que merece ser colocado em discussão.

\section{Considerações finais}

A amplitude da crise que o Brasil atravessa desde meados de 2016 se evidencia, no plano da educação, na crescente imposição de grupos conservadores que colocam respeito à diversidade como imoralidade, direitos humanos como um pejorativo "esquerdismo", pensamento crítico como doutrinação (Macedo, 2017). Em meio a essa ofensiva e a diversas formas de resistência que buscam preservar formas democráticas de pensar, discutir e deliberar sobre a educação como um direito social de formação de cidadania, uma gama de conteúdos vem sendo introduzida nas salas de aula: a Educação Financeira. No planejamento estratégico das instituições do mercado financeiro que a produzem, afirma-se como "desafio" retirar o tema do lugar secundário, complementar, que lhe foi atribuído na Proposta da Base Nacional Curricular Comum, para "torná-lo essencial, ou seja, parte do ambiente escolar, associado à cultura da escola, conforme proposto na proposta de Redirecionamento Estratégico" (AEF, 2016c, p. 14). Esse investimento apoia-se em conglomerados institucionais e produção de discursos e estratégias de ação muito mais amplas que as representadas pelos grupos nacionais.

A estrutura e as ações da Educação Financeira envolvem campos de fenômenos centrais em problematizações sobre o tempo presente: o universo das finanças - como conteúdos a serem introjetados pelos indivíduos em suas formas de vida - e processos sociais crescentemente globalizados - como forma 
organizacional que estabelece ligação e continuidade entre âmbitos internacional, nacionais e locais. Neste último, mais do que isso, a experiência brasileira reproduziu a estrutura internacional, seguindo à risca suas determinações. Desta maneira, correspondendo à INFE, criada e liderada pela OCDE no plano internacional, temos a ENEF, criada por decreto e implementada por instituições públicas e entidades privadas do mercado financeiro. Desenvolvem variedade de atividades educativas com objetivo de formar, informar e orientar indivíduos e sociedades a respeito de produtos, serviços e conceitos financeiros, estimulando o cultivo de valores e atitudes definidos como adequados a seu consumo dito sustentável e consciente. Embora destinem ações para públicos diversos, especial atenção é dedicada à educação de crianças e adolescentes em idade escolar, uma vez que consideram suas metas atingíveis principalmente no longo prazo.

É importante reter o que todo o empreendimento da Educação Financeira revela de um projeto de sociedade vislumbrado por elites políticas e econômicas. Não no sentido de um plano elaborado racionalmente por uma elite coesa e unificada. Propomos mais pensar em termos de interesses diversos reunidos sob perspectivas afins e que - mais importante por tratar-se de temas financeiros - não se apreende nem se explica exclusivamente por interesses econômicos. Se podemos entrever algo deste mundo previsto, talvez nele as finanças ocupem lugar central nos cotidianos, as estruturas de proteção social sejam irrelevantes e a maquinaria de gestão e controle financeiro seja controlada pelos atores deste mercado. Não é por acaso que no diagnóstico que oferece as bases para a Educação Financeira estejam as figuras do aposentado, do endividado e do "desbancarizado". A figura do trabalhador não aparece senão como sombra ou resquício desse mundo que as finanças vêm redefinir. Se a narrativa sobre o futuro está em construção, a sobre o presente se encontra em estágio avançado. A Educação Financeira (juntamente com as ações de Inclusão Financeira) pretende inserir no sistema o fluxo de recursos que ainda lhe é exterior, preparar os agentes que os produzem para participar do sistema sem comprometê-lo e movimentá-lo adquirindo proteção e "melhores condições de alcançarem suas metas e sonhos" (CVM, s/d.b, p. 57). Se é forçoso admitir, com o discurso oficial, que não se trata de proteção ao consumidor, não fica menos evidente, entretanto, que o consumidor é o sujeito projetado por este modelo.

Por essa razão, a Educação Financeira se apresenta e pretende como uma ação perene, constante, uma política de Estado, segundo os termos oficiais. Se alguns conteúdos são retirados da pauta escolar, há que se atentar para os que são acrescidos a ela. Colocando-se como solução a problemas identificados em leituras especializadas da realidade, a Educação Financeira acaba por definir os termos pelos quais os próprios problemas são formulados e compreendidos. Que o futuro do planeta e as formas de viver nele se imponham como questões à educação não há dúvida, mas um repertório muito específico para sua elaboração e enunciação está sendo incluído nas instituições escolares sem abertura e participação da sociedade interessada, graças, em grande medida, à estrutura organizacional que sustenta essa inserção. Ela conecta de maneira nebulosa grande variedade de organizações e entidades - públicas e privadas, nacionais e internacionais - com funções e recursos de poder pouco evidentes. A dificuldade colocada é de grande monta, já que a educação não pode abrir mão do reconhecimento de seu enraizamento local nem da pertinência do plano nacional, como campo de construção e disputa política. Como resolver tal paradoxo? Será possível transnacionalizar, como sugere Fraser para o problema da justiça, a disputa por uma concepção de educação? O caso da Educação Financeira constitui empreitada deste tipo, evidenciando simultaneamente o quanto afeta a educação nacional e local, estando longe de restringir-se a ela, e se desdobrando ao redor do globo. A imaginação política necessária para enfrentar este tipo de questão se beneficia também do melhor entendimento das forças em jogo, daí que o ajuste no olhar sobre os âmbitos em disputa não seja detalhe ou acessório, mas fundamental. 


\section{Notas}

1. Definição pela OCDE. Disponível em: http://www.vidaedinheiro.gov.br/wp-content/uploads/2017/04/InfograficoENEF-0508-1.pdf. Acesso em 15/08/2017.

2. Na medida em que o que tomamos aqui como Educação Financeira tem conteúdos específicos, produzidos em dado contexto e por organizações definidas, sempre a designaremos com as iniciais maiúsculas. Exceção feita a passagens como essa, em que a referência é à existência de outras ações que se denominam como de educação financeira, mas não partilham das particularidades que caracterizam nosso objeto.

3. Nos documentos e outras fontes de informação duas expressões são usadas concomitantemente: financial education e financial literacy. No Brasil, não existe essa diferenciação e a expressão educação financeira é a correntemente empregada. Assim, salvo em citações ou referências diretas a documentos (em que optamos por letramento financeiro), educação financeira designará o conjunto de atividades sobre o qual nos debruçamos.

4. Documento de 2012 citava 220 instituições públicas de 100 países (OCDE, 2012, p. 3). O portal da INFE registrava 240 instituições de 110 países, no final de 2017 e 260 de 115 países no final de 2018.

5. Integram o Coremec: Banco Central do Brasil, Comissão de Valores Mobiliários, Superintendência Nacional de Previdência Complementar e Superintendência de Seguros Privados (Decreto n. 5.685 de 2006).

6. Esta data varia segunda fonte: 2011, segundo Relatório Anual de Atividades de 2013 (AEF, 2013, p. 10); 2012, segundo Relatório Anual de 2017 (AEF, 2017, s/p) e certificação como Oscip em 2013, segundo site da organização.

7. Estes números também variam conforme a fonte: 20 mil estudantes de 868 escolas (Bruhn et. al., 2013: 3 ) e 26 mil alunos de 900 escolas (BMF\&Bovespa, 2012, p. 2).

8. "Ensino Médio Inovador" e "Mais educação".

9. No relatório de avaliação são apresentadas 14 habilidades, com expectativa de identificação variável segundo a série escolar, organizadas em chave denominada "Produção, consumo, cuidados, organização e planejamento". São elas: "Identificar o assunto de textos cujo tema seja atitudes socialmente responsáveis em relação ao meio ambiente; Localizar informações em textos que registram o consumo - de eletricidade, de água, de telefone entre outras possibilidades; Identificar a finalidade de textos e suportes textuais que registrem despesas, consumo, gastos; Reconhecer a finalidade de gêneros textuais relacionados à vida financeira - recibos, cheques, notas fiscais; Reconhecer situações nas quais estejam envolvidos conceitos relacionados à vida financeira: poupança, despesa, consumo, gastos, desperdício, risco, retorno, planejamento financeiro, investimento, entre outros; Identificar situações relacionadas a atitudes financeiramente responsáveis; Localizar informações em gráficos e tabelas que apresentem informações relacionadas à vida financeira (compras, vendas, gastos); Localizar informações em textos que circulam na esfera financeira: anúncios classificados, reportagens, entre outros; Estimar valores e/ou procedimentos necessários à realização de projetos financeiros; Diferenciar trabalho remunerado de trabalho não remunerado; Identificar a origem e o destino de produtos diversos e/ou aqueles que podem ser reciclados; Reconhecer situações socialmente responsáveis relacionadas ao espaço público e ao espaço privado; Identificar vantagens, desvantagens e riscos da realização de compras à vista e a prazo; Identificar informações implícitas em textos midiáticos que sejam relevantes para a tomada de decisões relativas à vida financeira”. (AEF, 2016b, p. 11).

10. Falhas de representatividade são passíveis de ocorrer mesmo em ambientes bem conformados à estrutura dos Estados nacionais. A questão da autora se coloca, como se verá a seguir, quando a participação igualitária é prejudicada pela consideração de âmbitos de disputa não coincidentes com os territórios delimitados no modelo keynesiano-westfaliano.

\section{Referências}

AEF - Associação de Educação Financeira. Relatório Anual 2012. São Paulo, 2012.

AEF - Associação de Educação Financeira. Relatório Anual de Atividades 2013. São Paulo, 2013.

AEF - Associação de Educação Financeira. Relatório Anual 2016. São Paulo, 2016a.

AEF - Associação de Educação Financeira. Relatório Técnico Final Projeto Piloto Programa Educação Financeira das Escolas: Ensino Fundamental. São Paulo, 2016b. Disponível em http://www.vidaedinheiro. gov.br/wp-content/uploads/2017/04/Projeto_Piloto_Ensino_Fundamental_Relatorio_Final_2016.pdf

AEF - Associação de Educação Financeira. Plano de Ação Biênio 2017-2018. São Paulo, 2016c. Disponível 
em http://www.vidaedinheiro.gov.br/wp-content/uploads/2017/04/03-03-2017-PLANOACAO.pdf

AEF - Associação de Educação Financeira. Relatório Anual 2017. São Paulo, 2017.

AFONSO, A.J. Reforma do Estado e Políticas Educacionais: entre a crise do Estado-Nação e a emergência da regulação supranacional. Educação \& Sociedade, Campinas, n. 75, p. 15-32, 2001.

BENDIX, R. Construção nacional e cidadania. Estudos de nossa ordem social em mudança. São Paulo: Edusp, 1996.

BM\&FBOVESPA. Resultados da Avaliação de Impacto do Projeto Piloto de Educação Financeira nas Escolas, 2012. Disponível em http://www.vidaedinheiro.gov.br/wp-content/uploads/2017/04/avaliacao_ educacao_financeira_escolas.pdf

BOURDIEU, P.; PASSERON, J-C. A reprodução. 3.ed. Rio de Janeiro: Francisco Alves, 1992.

BRASIL. Decreto n. 5.685, de 25 de janeiro de 2006. Institui o Comitê de Regulação e Fiscalização dos Mercados Financeiro, de Capitais, de Seguros, de Previdência e Capitalização - Coremec. Disponível em http://www.planalto.gov.br/ccivil_03/_Ato2004-2006/2006/Decreto/D5685.htm

BRASIL. Decreto n. 7.397, de 22 de dezembro de 2010. Institui a Estratégia Nacional de Educação Financeira - ENEF, dispõe sobre a sua gestão e dá outras providências. Disponível em http://www.planalto. gov.br/ccivil_03/_Ato2007-2010/2010/Decreto/D7397.htm

BRUHN, Mirian et al. O Impacto da Educação Financeira do Ensino Médio - Evidência Experimental do Brasil, Washington: Banco Mundial, 2013.

CUNHA, M.P. Silencioso e penetrante: o processo de financeirização a partir das instituições promotoras da inclusão financeira. Contemporânea Revista de Sociologia da UFSCar, São Carlos, v. 8, n. 2, p. 585-606, 2018. CVM - Comissão de Valores Mobiliários. Estratégia Nacional de Educação Financeira - ENEF, mimeo, s/d.a. CVM - Comissão de Valores Mobiliários. Anexos. Orientação para Educação Financeira nas Escolas. In: CVM. Estratégia Nacional de Educação Financeira - ENEF, mimeo, s/d.b, p. 56-85.

FRASER, N. From distribution to recognition? Dilemmas of justice in a "postsocialist age". New Left Review, London, v. 1, n. 212, p. 68-93, 1995.

FRASER, N. Reenquadrando a justiça em um mundo globalizado. Lua Nova, São Paulo, n. 77, p. 11-39, [2005] 2009.

LAVAL, C. et. al. La nouvelle école capitaliste. 1. ed. Paris: La Découverte, 2011.

LAZARUS, J. De l'aide à la responsabilisation - L'espace de l'éducation financière em France. Genèses, v. 4, n. 93, p. 76-97, 2013.

MACEDO, E. As demandas conservadoras do Movimento Escola sem Partido e a Base Nacional Curricular Comum. Educação \& Sociedade, Campinas, v. 38, n. 139, p. 507-524, 2017.

OCDE. Improving Financial Literacy. Analysis of Issues and Policies. Paris, 2005a. Disponível em https:// doi.org/10.1787/9789264012578-en 
OCDE. Recommendation on Principles and Good Practices for Financial Education and Awareness. Paris, 2005b. Disponível em https://www.oecd.org/finance/financial-education/35108560.pdf

OCDE. Minutes of the OECD-Brazilian International Conference on Financial Education, 15-16 December, 2009, Rio de Janeiro, Brasil. Paris, 2010.

OCDE. Annex A. INFE Guidelines for Financial Education in Schools. In: OCDE. Financial Education for Youth: the role of schools. Paris, 2012, p. 165-180. Disponível em http://doi.org/10.1787/9789264174825-6-en

SAVOIA, J.R.F. et al. Paradigmas da educação financeira no Brasil. Revista de Administração Pública, Rio de Janeiro, v. 41, n. 6, p. 1121-41, 2007.

\section{Sobre a Autora}

Márcia Pereira Cunha é Socióloga e doutora em Sociologia pela Universidade de São Paulo. Pesquisadora do LMI-SAGEMM (USP/IRD) e associada ao Laboratório Sophiapol (Paris-Nanterre). Membro da Rede Interdisciplinar de Pesquisadores Neoliberalismo e Políticas de Subjetivação (FFLCH-USP) e do grupo Neoliberalismo, Subjetivação e Resistências (IEA-USP). São temas de pesquisa: processos de transformação das políticas e discursos sobre cidadania, nas interfaces entre conhecimento técnico e participação política, racionalidade econômica e esferas não-econômicas da vida social, instituições internacionais e tradutores nacionais.

Recebido: 10 Jan 2019 